\title{
Concentrations of PGF-2 $\alpha$ and PGE-2 in the uterine venous blood of rabbits during pseudopregnancy and pregnancy*
}

\author{
Fiona D. C. Lytton† and N. L. Poyser \\ Department of Pharmacology, University of Edinburgh, 1 George Square, Edinburgh EH8 9JZ, \\ U.K.
}

\begin{abstract}
Summary. Peripheral plasma progesterone concentrations in intact and hysterectomized pseudopregnant rabbits decreased from Day 14. The rate of decrease in intact, but not in hysterectomized, rabbits accelerated on Day 17 and was associated with an increase in PGF-2 $\alpha$ levels in the uterine venous plasma. There was no change in uterine PGE-2 output during pseudopregnancy. In pregnant rabbits, peripheral plasma progesterone concentrations remained high up to Day 30 , and there was no increase in uterine venous plasma levels of PGF-2 $\alpha$ on Day 17. PGF-2 $\alpha$ levels were elevated in uterine venous plasma on Day 25 of pregnancy, but there was no concurrent decline in plasma progesterone concentrations. Uterine venous plasma levels of PGE-2 increased markedly after Day 11 of pregnancy and reached very high concentrations in some rabbits.
\end{abstract}

\section{Introduction}

Hysterectomy, indomethacin and prostaglandin (PG) F-2 $\alpha$ antibodies lengthen the lifespan of corpora lutea in the pseudopregnant rabbit (Asdell \& Hammond, 1933; O'Grady, Caldwell, Auletta \& Speroff, 1972; Caldwell, Auletta, Gordon \& Speroff, 1972). As PGF-2 $\alpha$ is luteolytic in the pseudopregnant rabbit (Gutknecht, Duncan \& Wyngarden, 1972), the evidence suggests that PGF- $2 \alpha$ is the uterine luteolytic hormone in this species. However, Carlson \& Gole (1978) did not find any increase in PGF-2 $\alpha$ levels at the end of pseudopregnancy in blood taken from the posterior vena cava. In the present study, PGF- $2 \alpha$ and PGE- 2 concentrations have been measured in plasma taken from the uterine vein, ear vein and aorta during pseudopregnancy and pregnancy, to investigate further the role uterine PGs may play in luteal function in the rabbit.

\section{Materials and Methods}

\section{Experiments}

Experiment 1. Four intact and 4 hysterectomized New Zealand White rabbits were injected intravenously with 500 i.u. hCG (Organon Laboratories Ltd., Morden, Surrey) between 15:00 and 15:30 h, the day of injection becoming Day 0 of pseudopregnancy. Blood samples $(2 \mathrm{ml})$ were collected into heparinized glass tubes from a marginal ear vein of each rabbit on alternate

* Reprint requests to Dr N. L. Poyser.

$\uparrow$ Present address: Department of Pharmacology, University of London, King's College, Strand, London WC2R 2LS, U.K. 
days of pseudopregnancy. All rabbits had two pseudopregnancies. The plasma was stored at $-20^{\circ} \mathrm{C}$ until assayed for progesterone.

Experiment 2. Forty-eight New Zealand White rabbits were made pseudopregnant as in Exp. 1. On selected days of pseudopregnancy, each rabbit was anaesthetized by an intravenous injection of urethane ( $7 \mathrm{ml} / \mathrm{kg}$ of $25 \%$ solution; May \& Baker Ltd, Dagenham) and heparinized by the concomitant injection of $1500 \mathrm{u}$ heparin $/ \mathrm{kg}$ (Pularin: Evans Medical Ltd, Liverpool). A midline, abdominal incision was made to expose the uterus and uterine veins. In the rabbit, the uterine vein has several prominent branches. Vessels draining the caudal part of one uterine horn also drain the vagina, and, in addition, anastomose to various degrees with vessels draining the caudal part of the other uterine horn (Del Campo \& Ginther, 1972). A branch of the uterine vein draining the cranial portion of the uterine horn was therefore freed of fat, and a 21-gauge Yale Microlance needle (Becton Dickinson \& Co., New Jersey, U.S.A.), to which was attached a $7-\mathrm{cm}$ length of narrow bore Silastic tubing (Dow Corning, Michigan, U.S.A.), was inserted into the vessel. Blood flowed freely into a chilled glass bottle, and a $20 \mathrm{ml}$ sample was collected from the uterine vein on each side. Samples of blood $(20 \mathrm{ml})$ were also collected from the marginal ear vein and aorta. Plasma was stored at $-20^{\circ} \mathrm{C}$ before being assayed for progesterone and PGs. All rabbits had their ovaries checked for the presence of corpora lutea and if they were not present in both ovaries, the results from that animal were discarded and the rabbit was replaced. Four rabbits were used on each day studied.

Experiment 3. New Zealand White rabbits of proven fertility were mated to male rabbits of proven fertility, the day of mating being Day 0 of pregnancy. Animals were anaesthetized and heparinized, blood samples were collected from the left and right uterine veins, the marginal ear vein and the aorta, and the plasma samples were stored, as described in Exp. 2. Rabbits used on Days 6 to 8 had their ovaries checked for the presence of corpora lutea while, in animals used after Day 8 , the number of fetuses in each uterine horn was noted. Animals, in which corpora lutea or fetuses were absent, were discarded and, if possible, replaced with another rabbit.

\section{Extraction and assay procedures}

Progesterone. Progesterone was measured by radioimmunoassay using an antibody raised and tested by Dighe \& Hunter (1974) and assessed for its suitability for use in this laboratory by Poyser \& Horton (1975). The antibody had adequate sensitivity (limit $18 \mathrm{pg} / \mathrm{tube}$ ) and specificity (see Table 1 in Poyser \& Horton, 1975), and the results obtained in the present study were in the expected range. For each plasma sample, two volumes (between 0.05 and $0.2 \mathrm{ml}$ ) were assayed in triplicate. The intra-assay coefficient of variation, calculated from triplicate results obtained for each sample assayed, was $8.5 \%$. The inter-assay coefficient of variation, calculated from the result obtained following the incorporation of $200 \mathrm{pg}$ in each assay, was 9.8\%.

Prostaglandins. PGF-2 $\alpha$ and PGE-2 were extracted from rabbit plasma and separated by silicic acid column chromatography as described by Blatchley, Donovan, Horton \& Poyser (1972), except that methanol was incorporated into the solutions for chromatography as outlined by Downie, Poyser \& Wunderlich (1974). In order to correct for procedural losses, $0.0013 \mu \mathrm{Ci}(3 \mathrm{pg})\left[{ }^{3} \mathrm{H}\right] \mathrm{PGF}-2 \alpha$ (sp. act. $160 \mathrm{Ci} / \mathrm{mmol}$; Radiochemical Centre, Amersham) was added to all plasma samples before extraction and $10 \%$ of the PGF fraction from the silicic acid columns was monitored for radioactivity. PGF- $2 \alpha$ values have therefore been corrected for recovery. The quantity of $\left[{ }^{3} \mathrm{H}\right] \mathrm{PGF}-2 \alpha$ used did not interfere with the radioimmunoassay. The rate of recovery was $50-60 \%$.

PGF-2 $\alpha$ was measured by an antibody raised in rabbits (Dighe, Emslie, Henderson, Rutherford \& Simon, 1975). It does not distinguish between PGF-2 $\alpha$ and PGF-1 $\alpha$, but has low cross-reactivities with other PGs and their metabolites (Poyser \& Scott, 1980). The limit of detection was $24 \mathrm{pg} /$ tube. Two volumes of each PGF fraction from the column were assayed in 
triplicate, and the intra-assay coefficient of variation, calculated from the triplicate results obtained, was $7.8 \%$. The inter-assay coefficient of variation, calculated from the results obtained by incorporating $250 \mathrm{pg}$ PGF- $2 \alpha$ in each assay, was $7.9 \%$.

It was considered inappropriate to use $\left[{ }^{3} \mathrm{H}\right] \mathrm{PGE}-2$ to monitor losses of PGE-2 because any incomplete separation of $\left[{ }^{3} \mathrm{H}\right] \mathrm{PGE}-2$ and $\left[{ }^{3} \mathrm{H}\right] \mathrm{PGF}-2 \alpha$ would have led to spurious results. Consequently, known amounts of PGE-2, together with $0.013 \mu \mathrm{Ci}\left[{ }^{3} \mathrm{H}\right] \mathrm{PGE}-2(160 \mathrm{Ci} / \mathrm{mmol}$; Radiochemical Centre, Amersham), were added to $10 \mathrm{ml}$ rabbit aortic plasma, solvent extracted and subjected to silicic acid column chromatography. The PGE fraction from the columns was monitored for radioactivity. The amounts of PGE- 2 added and the \% recovery of radioactivity (mean \pm s.e.m. for 3 determinations) were, respectively, $0 \mathrm{ng}, 49.4 \pm 0.9 \% ; 10 \mathrm{ng}, 51.4 \pm$ $2.6 \% ; 100 \mathrm{ng}, 52 \cdot 6 \pm 2 \cdot 1 \% ; 1000 \mathrm{ng}, 50 \cdot 1 \pm 1 \cdot 3 \%$. The average recovery of $\left[{ }^{3} \mathrm{H}\right] \mathrm{PGE}-2$ was therefore about $50 \%$.

PGE-2 was measured using an antibody raised in rabbits by $\mathrm{Dr} \mathrm{K}$. K. Dighe, using the procedure described by Dighe, Jones \& Poyser (1978). Assays were carried out in 0.05 M-phosphate buffer $(\mathrm{pH} 7 \cdot 5)$ which contained gelatin $(1 \mathrm{~g} / \mathrm{l})$ and sodium azide $(0 \cdot 1 \mathrm{~g} / \mathrm{l})$. The double-antibody method of separation was used. The antiserum cross-reacted as follows: PGE-2, 100\%; PGA-2, 13.6\%, PGB-2, 260\%; PGF-2 $\alpha, 2.5 \%$; PGD-2, 0.23\%; 6-oxo-PGF-1 $\alpha$, $0.63 \%$; thromboxane $\mathrm{B}_{2}, 0.08 \% ; 15$-oxo-PGE-2, $0.63 \% ; 13$,14-dihydro-15-oxo-PGE-2, $0.63 \%$; arachidonic acid, $\mathbf{0 . 2 3 \%}$. Although the antiserum has high cross-reactivity with PGA-2 and PGB-2, this was not considered a problem since these two PGs are eluted from silicic acid columns before PGE-2 (Davis \& Horton, 1972). The antiserum did not distinguish between PGE-2 and PGE-1; values obtained for PGE-2 were in the expected range. The detection limit of the assay was $40 \mathrm{pg} /$ tube. Two volumes of each PGE fraction from the columns were assayed in triplicate, and the intra-assay coefficient of variation, calculated from the triplicate results, was $8.5 \%$. The inter-assay coefficient of variation, calculated from the results obtained by incorporating $350 \mathrm{pg} \mathrm{PGE-2} \mathrm{in} \mathrm{each} \mathrm{assay,} \mathrm{was} 8.7 \%$. PGE-2 concentrations in plasma have not been corrected for recovery.

\section{Analysis by gas chromatography-mass spectrometry (GC-MS)}

Extracted and authentic prostaglandins were converted into methyl esterstrimethysilylethers (Me-TMS) or, if a keto group was present, into methyl esters-butyloximestrimethysilylethers (Me-BuO-TMS) as described by Fenwick, Jones, Naylor, Poyser \& Wilson (1977). Analyses were carried out on a VG Micromass $7070 \mathrm{~F}$ double focusing gas chromatogram-mass spectrometer, using the multiple ion detector (MID) unit. The glass column $(3 \mathrm{~m} \times 4 \mathrm{~mm}$ ) was packed with $3 \%$ OV1 on supelcoporte (Supelco Inc., Belleforte, U.S.A.), the helium gas flow was $30 \mathrm{ml} / \mathrm{min}$, and the column temperature was $265^{\circ} \mathrm{C}$. Before preparation of derivatives, $500 \mathrm{ng}\left[{ }^{2} \mathrm{H}\right] 6$-oxo-PGF-1 $\alpha$ were added to each extracted and authenticated PG sample. After injecting a sample into the machine, $\mathrm{m} / \mathrm{e}$ ions of the following values were monitored: 423 (characteristic of PGF-2 $\alpha$ at carbon value 23.8); 425 (PGF-1 $\alpha$, carbon value 24.4); 495 ( $\left[{ }^{2} \mathrm{H}\right] 6$-oxo-PGF-1 $\alpha$, carbon value 26.4); 508 (PGE-2, carbon values first isomer $25 \cdot 5$, second isomer $26 \cdot 1$; 6-oxo-PGF-1 $\alpha$, carbon value 26.4) and 510 (PGE-1, carbon values first isomer $25 \cdot 9$, second isomer $26 \cdot 2$; PGD-2, carbon values first isomer $25 \cdot 1$, second isomer 25.8). If sufficient quantities of extracted material were present, a full mass spectrum was also recorded. Extracted PGs from a particular blood vessel were pooled for analytical purposes, although samples from Exps 2 and 3 were kept separate.

Statistical tests. Results were analysed for homogeneity of variance using the $F$ test and comparisons made using the appropriate $t$ test (Sokal \& Rohlf, 1969). Correlations between uterine venous PGE concentrations and fetal number were with $\chi^{2}$ tests. 


\section{Results}

\section{Experiment 1}

Peak plasma progesterone levels in rabbits made pseudopregnant with an injection of 500 i.u. hCG were higher than those reported in rabbits made pseudopregnant by mating to a vasectomized male (Harrington \& Rothermel, 1977; Carlson \& Gole, 1978), but were similar to those found in rabbits made pseudopregnant with an injection of 50 or 100 i.u. hCG (Harrington \& Rothermel, 1977). Peripheral plasma progesterone levels in intact and hysterectomized animals increased from Day 0, reached maximum values between Days 8 and 14, and then declined (Table 1). However, progesterone levels in intact rabbits were significantly lower $(P<$ 0.05 ) than those in hysterectomized rabbits on Days 17, 18 and 19 of pseudopregnancy.

Table 1. Mean ( \pm s.e.m. for 4 determinations) concentrations of progesterone $(\mathrm{ng} / \mathrm{ml})$ in ear vein plasma from intact and hysterectomized (Hyst.) rabbits during pseudopregnancy

\begin{tabular}{rrrccc}
\hline Day & \multicolumn{1}{c}{ Intact } & Hyst. & Day & Intact & Hyst. \\
\hline 0 & $0.5 \pm 0.1$ & $0.7 \pm 0.03$ & 11 & $15.0 \pm 3.5$ & $15.2 \pm 1.3$ \\
1 & $1.4 \pm 0.1$ & $3.4 \pm 0.8$ & 12 & $10.5 \pm 1.0$ & $14.4 \pm 1.8$ \\
2 & $2.4 \pm 0.1$ & $2.6 \pm 0.2$ & 13 & $12.3 \pm 0.3$ & $12.2 \pm 0.8$ \\
3 & $4.3 \pm 1.9$ & $5.5 \pm 0.8$ & 14 & $8.7 \pm 0.6$ & $10.1 \pm 1.2$ \\
4 & $6.7 \pm 0.1$ & $7.7 \pm 0.2$ & 15 & $6.9 \pm 0.5$ & $8.9 \pm 1.8$ \\
5 & $7.0 \pm 1.2$ & $9.4 \pm 1.1$ & 16 & $4.5 \pm 1.1$ & $7.6 \pm 1.3$ \\
6 & $11.2 \pm 1.9$ & $12.4 \pm 1.5$ & 17 & $1.5 \pm 0.5^{*}$ & $5.8 \pm 0.5$ \\
7 & $11.6 \pm 2.3$ & $13.0 \pm 1.0$ & 18 & $1.5 \pm 0.2^{*}$ & $3.6 \pm 1.3$ \\
8 & $13.5 \pm 1.3$ & $15.5 \pm 1.6$ & 19 & $1.0 \pm 0.2^{*}$ & $3.0 \pm 0.8$ \\
9 & $18.5 \pm 3.0$ & $14.4 \pm 1.0$ & 20 & $0.9 \pm 0.3$ & $1.6 \pm 0.6$ \\
10 & $13.8 \pm 1.2$ & $17.4 \pm 2.2$ & & & \\
\hline
\end{tabular}

* Significantly lower than in hysterectomized rabbits $(P<0.05)$.

\section{Experiment 2}

Plasma progesterone concentrations were higher than in Exp. 1 although a similar profile was observed (Text-fig. 1). These higher levels may be due to the stress of the operation because the ear vein blood samples were collected after blood samples had been obtained from the uterine veins. PGF- $2 \alpha$ levels in plasma from the aorta and ear vein were about $0.4 \mathrm{ng} / \mathrm{ml}$ and showed little change throughout pseudopregnancy. PGF-2 $\alpha$ levels in plasma from the uterine vein were higher than in plasma from the aorta by an average of $0.42 \mathrm{ng} / \mathrm{ml}$, between Days 6 and 16 of pseudopregnancy. There was a significant increase in uterine venous plasma levels of PGF-2 $\alpha$ on Day $17(P<0.05)$, but not on Days 15 and 16, when compared to Day 14 levels (Day 14 being the day after which peripheral plasma progesterone levels decline). Although uterine venous plasma levels of PGF- $2 \alpha$ were also higher on Day 18 than on Day 14, this difference was not statistically significant.

PGE-2 levels were low in plasma from all three blood vessels and showed little variation during pseudopregnancy. Between Days 6 and 16, PGE-2 levels in the uterine venous plasma were higher than in plasma from the aorta by an average of $0.35 \mathrm{ng} / \mathrm{ml}$. When PGE-2 levels were corrected for a mean recovery of $50 \%$, this difference became $0.7 \mathrm{ng} / \mathrm{ml}$, suggesting that, between Days 6 and 16, PGE-2 output from the pseudopregnant rabbit uterus is higher than PGF- $2 \alpha$ output. However, the average difference in PGE-2 levels was not increased on Days 17 and 18 , in contrast to plasma PGF- $2 \alpha$ levels which showed differences between the uterine vein and aorta of 4.1 and $2.0 \mathrm{ng} / \mathrm{ml}$ on Days 17 and 18 respectively. An increase in uterine PGF-2 $\alpha$ output occurred therefore without any increase in PGE-2 output. 


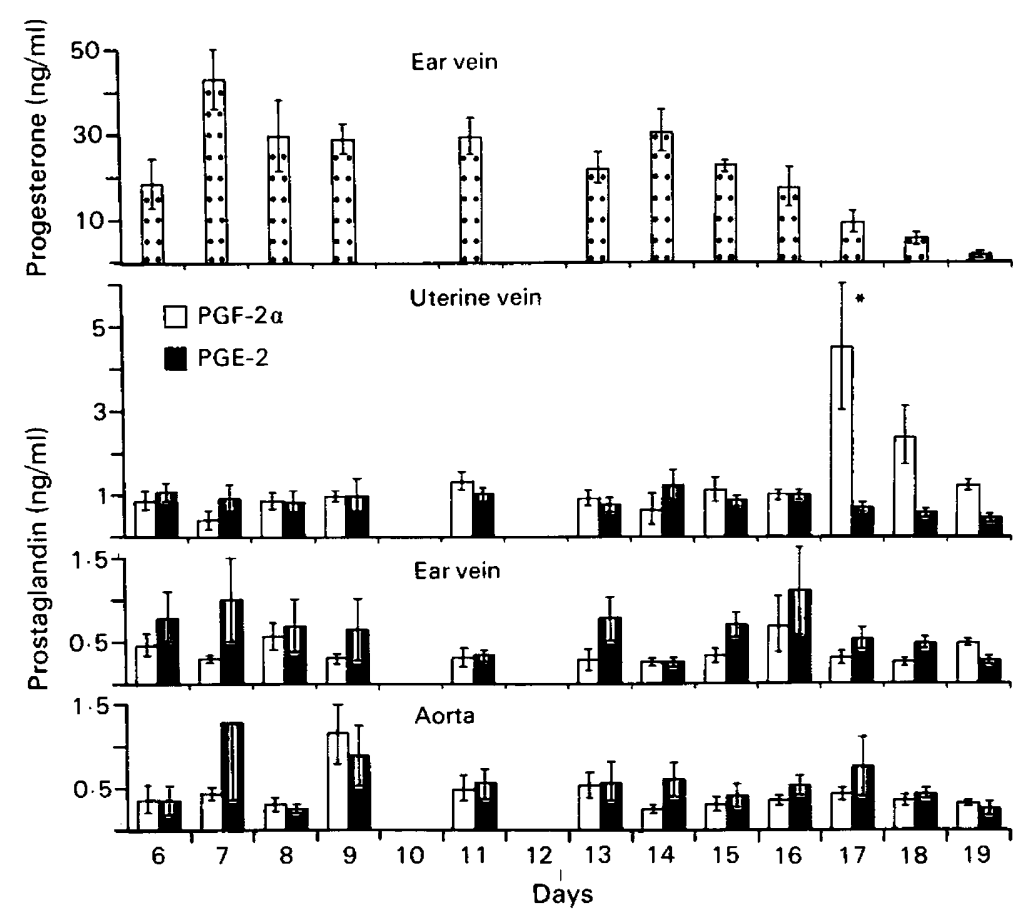

Text-fig. 1. Mean ( \pm s.e.m.) plasma concentrations ( 4 determinations from the ear vein and aorta, and 8 determinations from the uterine vein) of PGF-2 $\alpha$, PGE-2 and progesterone during pseudopregnancy in the rabbit. *Significantly raised $(P<0.05)$.

Analysis of the samples by GC-MS was inconclusive. The amounts of PGF-2 $\alpha$ and PGE-2 remaining in the samples after radioimmunoassay were too low for their characteristic $\mathrm{m} / \mathrm{e}$ ions to penetrate above the "background noise" of ions produced by the biological sample.

\section{Experiment 3}

Peripheral plasma progesterone levels in pregnant rabbits increased from Day 0, peaked by Days 16-17, were lower than peak values during the second half of pregnancy and then declined on Day 31 (Text-fig. 2) (see also Challis, Davies \& Ryan, 1973; Fuchs, 1978). Levels of PGF-2 $\alpha$ in plasma from the aorta and ear vein were again low and showed little variation during pregnancy. Uterine venous plasma levels of PGF-2 $\alpha$ were slightly higher than peripheral values, but no increase was found on Days 17 and 18 of pregnancy. However, PGF- $2 \alpha$ levels in uterine venous plasma were significantly higher on Day $25(P<0.05)$ than on Days 23,24 or 27 of pregnancy, although this increase was not associated with a decline in plasma progesterone levels.

In rabbits which were in the early stages of labour on Days 31 and 32 (as indicated by a dilated cervix and fetuses beginning to move towards the vagina), PGF- $2 \alpha$ levels in uterine venous plasma were higher $(P=0.05)$ than in rabbits not in labour. In one post-partum rabbit, PGF-2 $\alpha$ levels in plasma from all three blood vessels were low (Text-fig. 2 ).

$\overline{P G E}-2$ levels were low in plasma from the ear vein and aorta throughout pregnancy, and in plasma from the uterine vein up to Day 8. However, after Day 11 PGE-2 levels in uterine venous plasma markedly increased and some very high values were recorded (Text-fig. 3 ). There was a positive correlation $(P<0.05)$ between uterine venous plasma PGE-2 levels and the number of fetuses in a uterine horn, suggesting that the PGE-2 is being secreted by the feto-placental unit. 


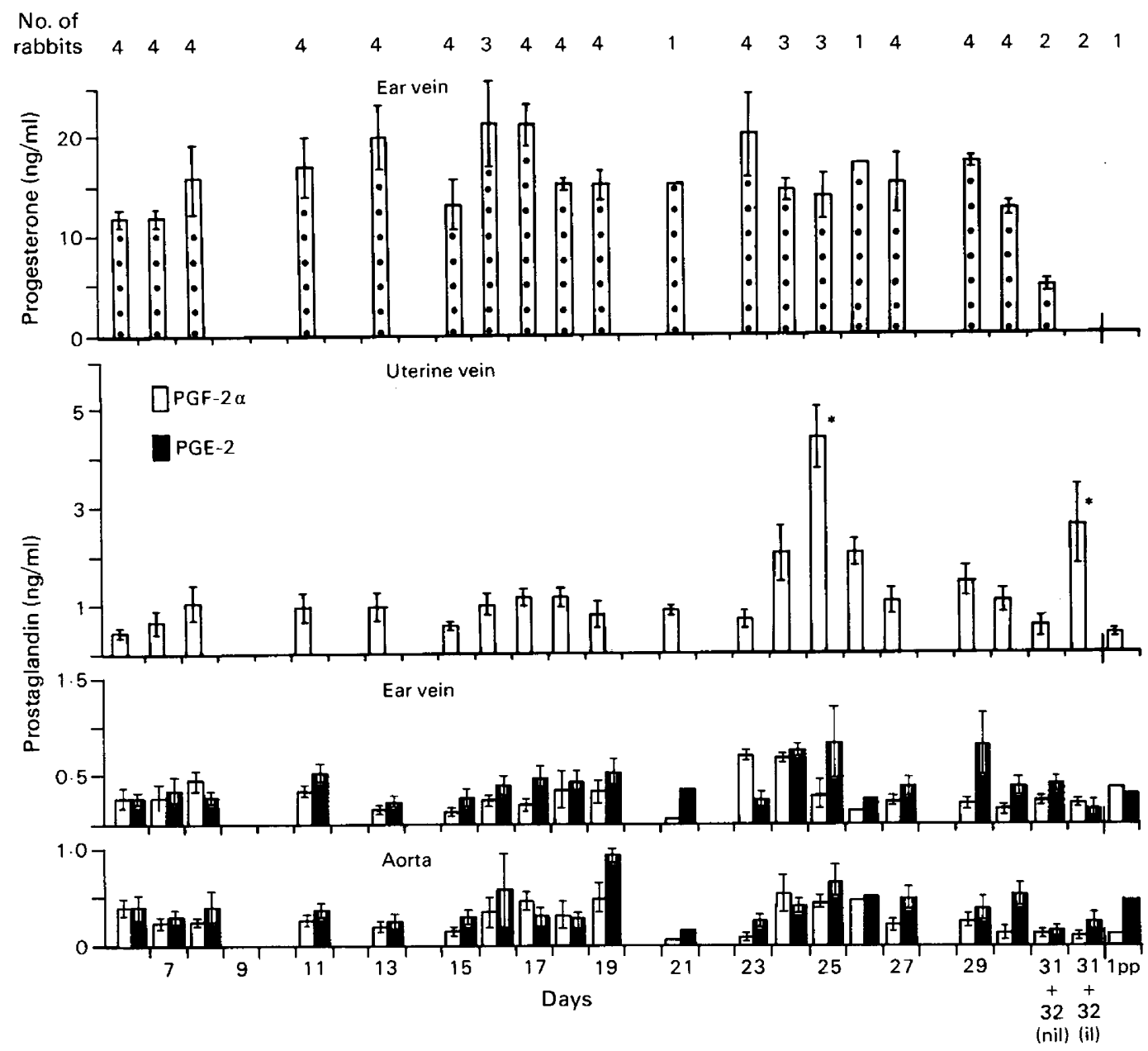

Text-fig. 2. Mean ( \pm s.e.m.) plasma concentrations ( 1 determination per rabbit from the ear vein and aorta, and 2 determinations per rabbit from the uterine vein) of PGF-2 $\alpha$, PGE- 2 and progesterone during pregnancy. Uterine vein PGE-2 values are shown in Text-fig. 3 (see text). nil, not in labour; il, in labour; pp, post partum. *Significantly raised $(P \leqslant 0.05)$.

In a rabbit on Day 1 post partum, uterine venous plasma levels of PGE-2 were again very low $(0.34 \mathrm{ng} / \mathrm{ml})$.

The amounts of PGE-2 and PGF-2 $\alpha$ in samples from the ear vein and aorta were too low for detection by GC-MS. PGE-2 was identified in uterine venous plasma both by the MID unit and by taking a full mass spectrum at the appropriate carbon value. PGE-1 was not detected. A peak corresponding to the $\mathrm{m} / \mathrm{e}$ ion of 423 was observed on the MID unit at the correct carbon value for PGF-2 $\alpha$, thus confirming the presence of this compound in uterine venous plasma. A peak corresponding to the $\mathrm{m} / \mathrm{e}$ ion of 491 at the correct carbon value for 6-oxo-PGF-1 $\alpha$ was also observed in the PGF fraction following silicic acid column chromatography of the uterine venous plasma extracts from pregnant rabbits.

\section{Discussion}

Peripheral plasma progesterone concentrations decreased from about Day 14 of pseudopregnancy in intact and hysterectomized rabbits, showing that the initial demise of the corpora 


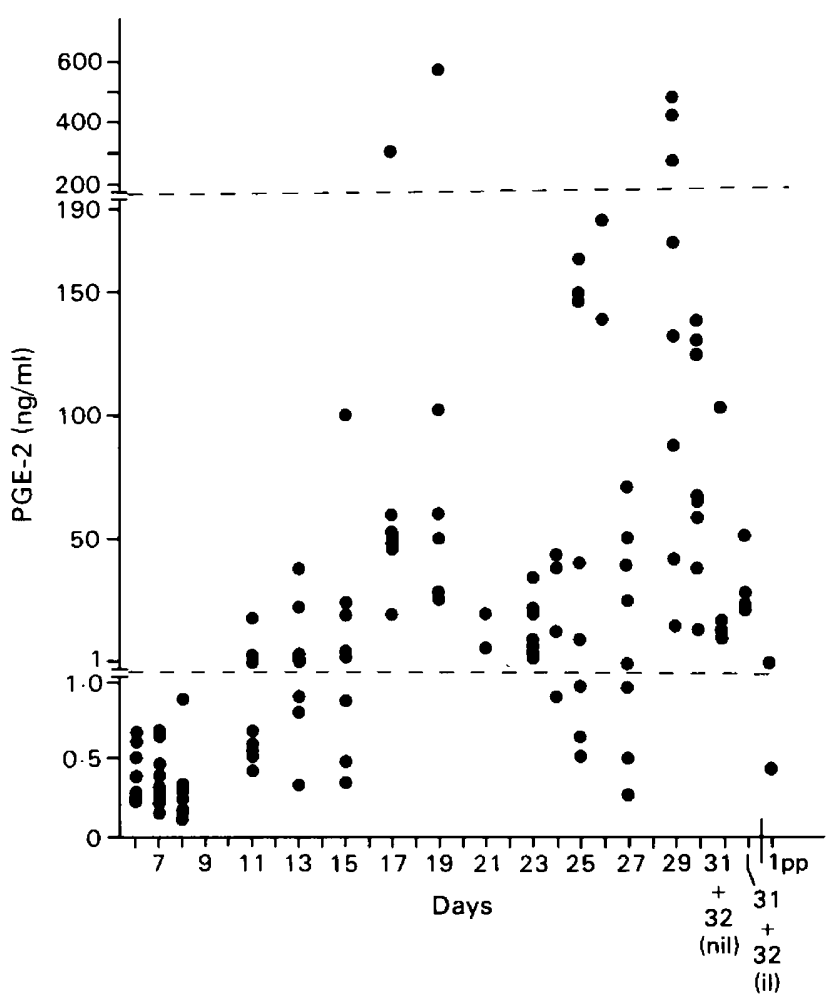

Text-fig. 3. Plasma concentrations of PGE-2 in the uterine vein during pregnancy in rabbits. Each point is 1 determination; 2 determinations per rabbit; number of rabbits as in Text-fig. 2 . nil, not in labour; il, in labour; pp, post partum.

lutea does not depend upon the presence of the uterus. The decline in plasma progesterone concentrations accelerated in intact but not in hysterectomized rabbits on Day 17 of pseudopregnancy, and this was associated with an increase in PGF-2 $\alpha$ concentrations in the uterine venous plasma. No increase in PGE-2 concentrations in the uterine venous plasma was observed, indicating that PGF-2 $\alpha$ is specifically synthesized by and released from the uterus near the end of pseudopregnancy and contributes to the final demise of the corpora lutea in intact rabbits. This study supports the conclusion that PGF-2 $\alpha$ is the uterine luteolytic hormone in the rabbit, as in other species (see Horton \& Poyser, 1976).

In pregnant rabbits, uterine PGF-2 $\alpha$ plasma concentrations were not elevated on Days 17 and 18 as in pseudopregnant rabbits. This lack of PGF- $2 \alpha$ secretion may be beneficial for the maintenance of corpora lutea during pregnancy, although luteotrophic factor(s) secreted by the placenta are largely responsible for maintaining luteal function beyond Day 14 (Schofield, 1960; Laudanski, Batra \& Akerlund, 1979).

There was an increase in uterine venous plasma concentrations of PGF-2 $\alpha$ on Days 24 and 25 of pregnancy without any decline in peripheral plasma concentrations of progesterone. Removal of fetuses, leaving the placentae in situ, on Day 25 of pregnancy does not prevent delivery of the placentae from occurring at the normal time, but fetectomy on Day 21 prevents placental delivery (Chiboka, Casida \& First, 1977). The increased output of PGF-2 $\alpha$ on Days 24 and 25 may be related to the change to autonomy/ for delivery of the placentae between Days 21 and 25, although the significance of this increase is not clear. Nevertheless, rabbits immunized against PGF-2 $\alpha$ and made pregnant abort about Day 24 (Elzayat \& Stylos, 1974). 
Our study was not particularly concerned with detailed investigation into uterine PGF-2 $\alpha$ output at term but, from the limited number of rabbits studied, peripheral plasma progesterone levels declined apparently without any increase in uterine venous plasma levels of PGF- $2 \alpha$. Indomethacin treatment of pregnant rabbits near term either does not prevent (Challis et al. 1975 ) or only partly slows the decline in plasma progesterone levels (Davies, Yoshinaga \& Ryan, 1976). However, indomethacin treatment delays parturition by up to 2 days suggesting that PGs are involved in this process and, indeed, uterine venous plasma concentrations of PGF- $2 \alpha$ were raised in 2 rabbits which were in the early stages of labour.

Concentrations of PGE-2 were low and varied little in plasma from the aorta and ear vein during pseudopregnancy and pregnancy, and from the uterine vein during pseudopregnancy. However, concentrations of PGE-2 in uterine venous plasma were markedly elevated after Day 11 of pregnancy. Similar high levels have been reported by Venuto, O'Borisio, Stein \& Ferris (1975) and Meese, Fischer, Hoffman \& Frolich (1980). Since PGE-2 stimulates progesterone output from the corpora lutea of several species (see Goldberg \& Ramwell, 1975), PGE-2 may form part of the placental luteotrophic stimulus. However, plasma progesterone levels decline at the end of pregnancy while uterine venous plasma levels of PGE-2 are still high, suggesting that ovarian progesterone output is not controlled by PGE- 2 .

Rabbits immunized against PGE-2 and made pregnant suddenly die after mid-pregnancy. Post-mortem examinations reveal that the effect of the antibodies is not directed towards the ovary (again implying that ovarian progesterone output is not controlled by uterine PGE-2), but rather towards the placenta, indicating that the PGE-2 produced locally may have a physiological role in placental growth and function (Elzayat \& Stylos, 1974).

Aortic plasma concentrations of PGE-2 remained constantly low during pregnancy, despite the large increase in PGE-2 concentrations in the uterine venous plasma. The lungs must therefore remove PGE-2 efficiently from the venous blood, and the enhanced inactivation of PGE-2 by the rabbit lung during pregnancy (Bedwani \& Marley, 1975), due mainly to a 20-fold increase in lung PG dehydrogenase activity (Sun \& Armour, 1974), may be of importance in this respect.

This study was supported by a grant from the M.R.C. Authentic prostaglandins were kindly supplied by the Upjohn Co., U.S.A.

\section{References}

Asdell, S.A. \& Hammond, J. (1933) The effects of prolonging the life of the corpus luteum in the rabbit by hysterectomy. Am. J. Physiol. 103, 600-605.

Bedwani, J.R. \& Marley, P.B. (1975) Enhanced inactivation of prostaglandin E-2 by the rabbit lung during pregnancy or progesterone treatment. $B r . J$. Pharmac. 53, 547-554.

Blatchley, F.R., Donovan, B.T., Horton, E.W. \& Poyser, N.L. (1972) The release of prostaglandins and progesterone into the utero-ovarian venous blood of guinea-pigs during the oestrous cycle and following oestrogen treatment. J. Physiol., Lond. 228, 69-88.

Caldwell, B.V., Auletta, F.J., Gordon, J.W. \& Speroff, L. (1972) Further studies on the role of prostaglandins in reproductive physiology. In Prostaglandins in Fertility Control, pp. 217-233. Eds S. Bergström, K. Green \& B. Samuelsson. World Health Organisation, Stockholm.

Carlson, J.C. \& Gole, J.W.D. (1978) CL regression in the pseudopregnant rabbit and the effects of treatment with prostaglandin F-2 $\alpha$ and arachidonic acid. J. Reprod. Fert. 53, 381-387.
Challis, J.R.G., Davies, I.J. \& Ryan, KJ. (1973) The relationship between progesterone and prostaglandin $F$ concentrations in the plasma of pregnant rabbits. Prostaglandins 4, 509-516.

Challis, J.R.G., Davies, I.J. \& Ryan, K.J. (1975) The effects of dexamethasone and indomethacin on the outcome of pregnancy in the rabbit. J. Endocr. 64, 363-370.

Chiboka, D., Casida, L.E. \& First, N.L. (1977) Role of rabbit fetuses and placentas in the maintenance of gestation and parturition. J. Anim. Sci. 45, 776784.

Davies, I.J., Yoshinaga, K. \& Ryan, K.J. (1976) The effects of combined dexamethasone and indomethacin treatment on the outcome of pregnancy in the rabbit. Biol. Reprod. 15, 551-554.

Davis, H.A. \& Horton, E.W. (1972) Output of prostaglandins from the rabbit kidney, its increase on renal nerve stimulation and its inhibition by indomethacin. Br.J. Pharmac. 36, 658-675.

Del Campo, C.H. \& Ginther, O.J. (1972) Vascular anatomy of the uterus and ovaries and the unilateral 
effect of the uterus: guinea-pigs, rats, hamsters and rabbits. Am. J. vet. Res. 33, 2561-2578.

Dighe, K.K. \& Hunter, W.M. (1974) A solid-phase radioimmunoassay for plasma progesterone. Biochem. J. 142, 219-231.

Dighe, K.K., Emslie, H.A., Henderson, L.K., Rutherford, F. \& Simon, L. (1975) The development of antisera to prostaglandins B-2 and F-2 $\alpha$ and their analysis using solid-phase and double antibody radioimmunoassay methods. Br. J. Pharmac. 55, 503-514.

Dighe, K.K., Jones, R.L. \& Poyser, N.L. (1978) Development of a radioimmunoassay for measuring 6-oxo-prostaglandin-F-1 $\alpha$. Br.J. Pharmac. 63, 406P.

Downie, J., Poyser, N.L. \& Wunderlich, M. (1974) Levels of prostaglandins in human endometrium during the normal menstrual cycle. J. Physiol., Lond. 236, 465-472.

Elzayat, S. \& Stylos, W.A. (1974) The effect of circulating antibodies on reproduction in rabbits with special reference to the placenta. Endocrinology 95, 1642-1648.

Fenwick, L., Jones, R.L., Naylor, B., Poyser, N.L. \& Wilson, N.H. (1977) Production of prostaglandins by the pseudopregnant rat uterus, in vitro, and the effect of tamoxifen with the identification of 6 keto-prostaglandin $\mathrm{F}-1 \alpha$ as a major product. $B r . J$. Pharmac. 59, 191-199.

Fuchs, A.R. (1978) Hormonal control of myometrial function during pregnancy and parturition. Acta endocr., Copenh., Suppl. 221, 1-69.

Goldberg, V.J. \& Ramwell, P.W. (1975) Role of prostaglandins in reproduction. Physiol. Rev. 55, 325-351.

Gutknecht, G.D., Duncan, G.W. \& Wyngarden, L.J. (1972) Inhibition of prostaglandin F-2 $\alpha$ in $\mathrm{LH}$ induced luteolysis in the pseudopregnant rabbit by 17 $\beta$-estradiol. Proc. Soc. exp. Biol. Med. 139, $406-410$.

Harrington, F.E. \& Rothermel, J.D. (1977) Daily changes in peripheral plasma progesterone concentrations in pregnant and pseudopregnant rabbits. Life Sci. 20, 1333-1340.
Horton, E.W. \& Poyser, N.L. (1976) Uterine luteolytic hormone: a physiological role for prostaglandin F-2a. Physiol. Rev. 56, 595-651.

Laudanski, T., Batra, S. \& Akerlund, M. (1979) Prostaglandin-induced luteolysis, in pregnant and pseudopregant rabbits and the resultant effects on the myometrial activity. J. Reprod. Fert. 56, 141-148.

Meese, C.O., Fischer, C., Hofiman, L.H. \& Frolich, J.C. (1980) Assessment of uterine and renal prostaglandin synthesis in pregnancy by gas chromatography-mass spectrometry. In Prostaglandins and Reproductive Physiology, pp. 167-177. Eds A. Crastes de Paulet, H. Thaler-Dao \& F. Dray. INSERM, Paris.

O'Grady, J.P., Caldwell, B.V., Auletta, F.J. \& Speroff, L. (1972) The effects of an inhibitor of prostaglandin synthesis (indomethacin) on ovulation, pregnancy and pseudopregnancy in the rabbit. Prostaglandins 1, 97-106.

Poyser, N.L. \& Horton, E.W. (1975) Plasma progesterone levels in guinea-pigs actively immunized against prostaglandin $\mathrm{F}-2 \alpha$, hysterectomized or treated with intra-uterine indomethacin. $J$. Endocr. 67, 81-88.

Poyser, N.L. \& Scott, F.M. (1980) Prostaglandin and thromboxane production by the rat uterus and ovary in vitro during the oestrous cycle. J. Reprod. Fert. $60,33-40$.

Schofield, B.M. (1960) Hormonal control of pregnancy by the ovary and placenta in the rabbit. J. Physiol., Lond. 151, 578-590.

Sokal, R.S. \& Rohlf, F.J. (1969) Biometry. The Principals and Practice of Statistics in Biological Research, pp. 175-252. W. H. Freeman and Co., San Francisco.

Sun, F.F. \& Armour, S.B. (1974) Prostaglandin 15hydroxydehydrogenase and $\Delta^{13}$-reductase levels in the lungs of maternal. fetal and neonatal rabbits. Prostaglandins 7, 327-338.

Venuto, R.C., O'Borisio, T., Stein, J.H. \& Ferris, T.F. (1975) Uterine prostaglandin E secretion and uterine blood flow in the pregnant rabbit. J. clin. Invest. 55, 193-197. 